\section{Hattrick in Hamburg}

Der Intensivkurs Muskuloskelettale Radiologie (IMR) hat den Hattrick geschafft: Zum dritten Mal fand der IMR am 13. und 14. September 2019 in Hamburg statt. Hochkarätige Referenten und ein abwechslungsreiches Programm sorgten für einen Besucherrekord.

Im Mittelpunkt des dritten IMR stand die muskuloskelettale Gelenkdiagnostik, mit Fokus auf Handgelenk und Hand, das Kniegelenk sowie die Wirbelsäule. „Wir sind stolz darauf, dass wir für den dritten Intensivkurs wieder renommierte Expertinnen und Experten der muskuloskelettalen Bildgebung aus Deutschland und Österreich gewinnen konnten, die die ganze Bandbreite vom praxisrelevanten Basiswissen bis hin zum Spezialisten-Know-how abdecken“, zeigt sich Tagungsleiter Prof. Dr. Marc Regier erfreut. Neu in diesem Jahr waren

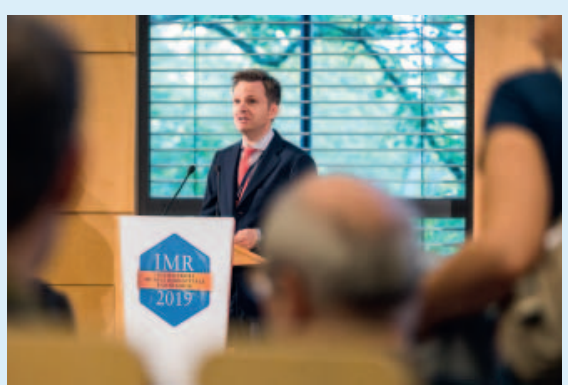

IMR-Tagungsleiter Prof. Dr. Marc Regier. Foto: DRG/Rafalzyk.

mehrere interaktive Sessions, mit TEDQuiz sowie Fallbeispielen aus der DRG-Lernplattform conrad, anhand derer die Referierenden ihr strukturiertes Vorgehen in der klinischen Routine mithilfe vollständiger DICOM-Studien zeigten.

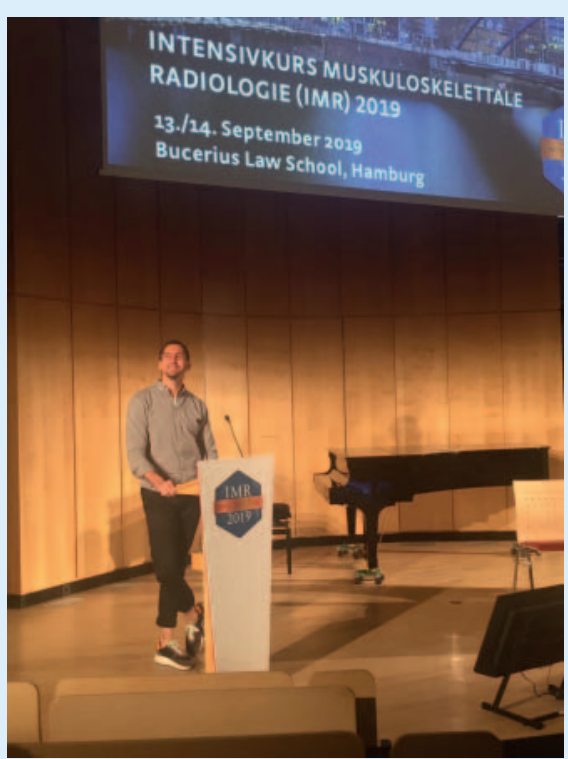

Überraschungsgast: René Adler beim IMR in Hamburg. Foto: DRG/Bachmann. 


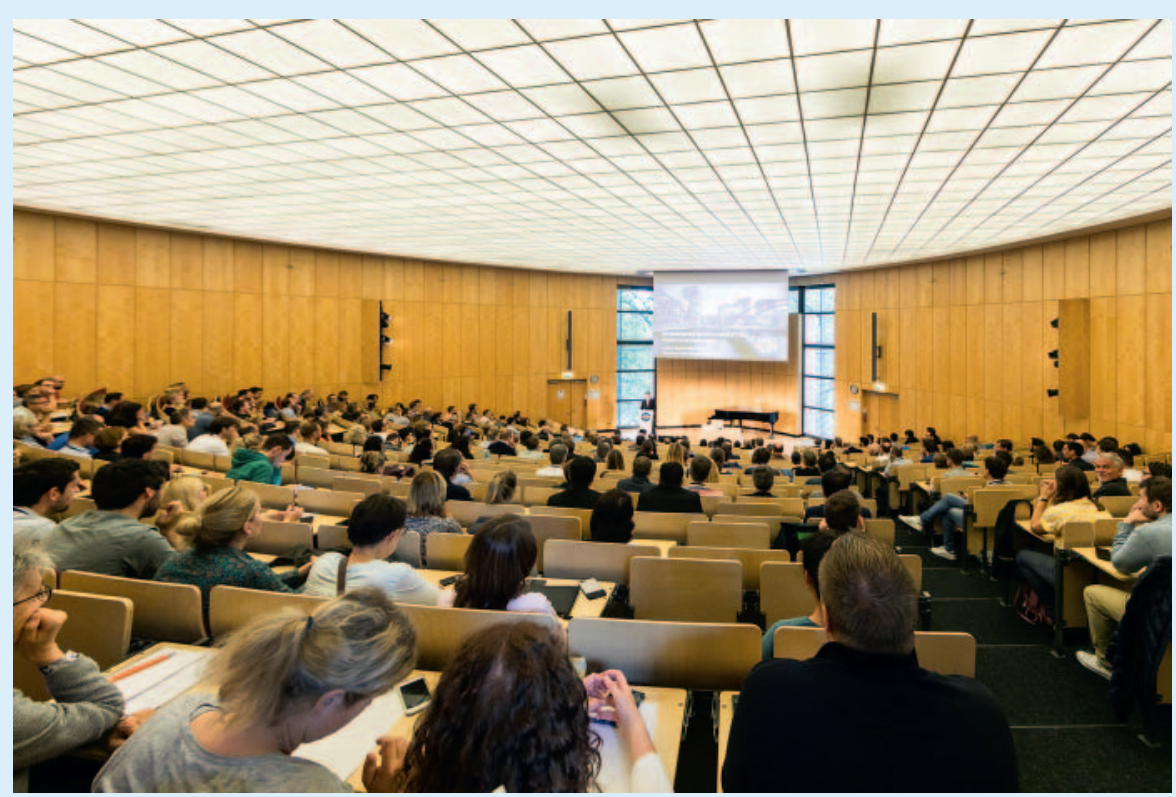

Neuer Besucherrekord: 350 Teilnehmerinnen und Teilnehmer waren beim IMR 2019 dabei. Foto: DRG/Rafalzyk.

\section{Überraschungsgast und Besucherrekord}

Unter dem Titel „Radiologie trifft Sportmedizin" gaben die Experten Einblicke in aktuelle Fallbeispiele und die Betreuung der genen Erlebnis zu machen. Mit 350 Teilnehmerinnen und Teilnehmern toppte der IMR 2019 zudem die Veranstaltung des Vorjahres, bei der 250 MSK-Interessierte dabei waren.

\section{Ab 2020: IMR mit 2 Austragungsorten}

Ab kommendem Jahr wird der IMR erstmals an 2 Orten seine Gäste begrüßen dürfen. Im Februar 2020 feiert der Intensivkurs seine Würzburger Premiere, um künftig auch aus dem süddeutschen Raum gut erreichbar zu sein. Die Veranstaltung bleibt aber auch künftig Hamburg treu und geht Ende August 2020 in ihre vierte Runde in der Hansestadt.

\section{SAVE THE DATE}

14.-15. Februar 2020, IMR Würzburg 28.-29. August 2020, IMR Hamburg

\section{Mehr Informationen:}

www.drg.de > IMR 2020 